\title{
The advantages and disadvantages of body language in Intercultural communication
}

\author{
Miramar Damanhouri \\ King Abdulaziz University, Saudi Arabia
}

\section{Introduction}

The rapid development of globalization has led to the need for communication between people with different cultural and linguistic backgrounds. Today, English is a world language for business, science and technology, so learning English as a second language has become a basic element of the Saudi education system in order to comply with the local and global market needs (Damanhouri, 2015). In both private and government-run universities, English is the medium of teaching and communication in many fields of study, especially in science and technology. Consequently, all students of King Abdulaziz University are obliged to study four English levels as part of the preparatory year program in order to choose their desired field of study. This resulted in the establishment of the English language Institute(ELI), which caters to all preparatory year students. Since there are nearly 150 foreign instructors in the ELI, I became interested in exploring the importance of non-verbal communication in intercultural settings, and to what extent nonverbal communication contributes to the success of communication. A large number of studies have focused on the challenges facing students who are studying English in English-speaking countries; however, this study explores the challenges facing English-language instructors with different cultural backgrounds who are teaching in Saudi Arabia, an Arabic-speaking country. The focus of this study is the understanding of non-verbal communication, specifically body language, in communication between Saudis and those of other cultures, bearing in mind the various interpretations of body movement among different cultural groups.

\section{Literature Review}

Before studying intercultural communication, it is important to understand what culture is and how it is passed from one generation to another. According to Bassis, Gelles, Richard and Levin (1991:66), "Culture itself is passed from one 
generation to the next through socialism - through children's stories and games, poems, religious rituals, jokes and other learning activities". Communication is the means by which the main elements of every culture, such as beliefs, values, norms, symbols, and language, are transmitted; successful communication requires understanding both verbal and nonverbal messages. Nonverbal communication plays an essential role in the process of face-to-face interaction, as it constitutes two-thirds of communication (Mcneill, 2000). According to Aghayeva (2011:53), "Nonverbal communication refers to all intentional and unintentional stimuli between communicating parties... Characteristic to nonverbal communication is that it is less systematized than verbal communication; it is culture bound and ambiguous". It includes all the elements of communication, aside from the words themselves, that contribute to the interpretation of the meaning hidden below the surface of the message (Burgeon, Buller, and Woodall, 1989). When people do not speak the same language, nonverbal communication is an important tool, because people tend to look for nonverbal cues in intercultural communication when the language barrier creates difficulties in understanding verbal messages. In fact, nonverbal communication reflects our cultural values and backgrounds, even in cases of intercultural communication.

Body language is an important element of nonverbal communication. Body language includes facial expressions such as smiling, frowning, and eye contact, physical gestures such as movements of the hand and the head, and proxemics, which refers to the space between communicators. Gullberg (2013) indicates that body language reflects and interacts with cultural, linguistic, and cognitive aspects of communication, and displays systematic variations across a range of measures in each of these aspects. Body movements help organize thoughts, facilitate expressions, and clarify and highlight messages. Some elements of body language are international and others are culture-specific. Universal similarities in body language express basic human emotions such as anger, sadness, fear, interest, or joy. Some aspects of body language are realized under unconsciousness, while others are under consciousness (Gulsunler and Fidan, 2011). The enlargement of eyeballs while being interested in something, and touching the mouth and nose to express insecurity, are examples of expressions and gestures made under unconsciousness, whereas gritting teeth and holding a fist up to threaten someone is an action made under consciousness(Gulsunler and Fidan, 2011).

Many researchers have discussed the importance of body language in communication. For Novinger (2001), nonverbal gestures or behaviors support verbal messages, and according to Sharifiabad and Vali (2001), nonverbal elements of communication help us express our ideas and feelings without using any words. This indicates that body language can be used to enhance the meaning of verbal 
messages, or even to replace them. The use of body language is often determined by factors such as "cultural background, socioeconomic background, education, gender, age, personal preferences and idiosyncrasies" (Varner, 2005:176), or hierarchical systems, levels of formality, or dimensions of masculinity and/or femininity (Kirkegaard, 2010). Context is another factor that should be considered. According to Katan (2004:245), "Context is "stored information...[that] the other person can be expected to possess on a given subject". Context plays a role in understanding any message, whether verbal or nonverbal. However, in intercultural settings, body movement cannot fully replace verbal messages, because of the need for explicit words and information, especially if those movements are culturespecific. On the other hand, among people of the same background, body movements can support or even replace verbal messages because the people who are communicating understand each other without saying too much.

Another factor in communication is register, or level of formality. For example, it is generally not considered polite to move one's hands excessively when talking to older people or when in a formal situation, while it is more acceptable to use hand gestures and/or facial expressions when talking amongst friends while greeting or joking with one another.

Burgoon, Buller and Woodall (1996:5) remark that in intercultural communication "Nonverbal communication can lead to misunderstanding as well as to understanding". This is because the interpretation of any message depends on the perception of the recipient(s) of the messages. People from different cultural backgrounds may perceive the same utterances or actions differently. This is the main reason why misunderstanding occurs in intercultural communication. For example, touching another person with one's hand, or making eye contact, may be interpreted as overly intimate or threatening (Ozuorcun, 2013). According to Anderson, Peter, Hecht, Hoobler and Smallwood (2002:90), "Intercultural interactions are always problematic. Linguistic barriers in many intercultural transactions are compounded by differences in nonverbal behaviors". In their study, which examines the role of nonverbal communication in intercultural communication, specifically in English as a foreign language classroom, Shi and Fan (2010) indicate that inappropriate nonverbal behaviors may cause miscommunication between Chinese students and American instructors. They suggest incorporating nonverbal communication skills into English language teaching in order to help English learners become fully competent in the targeted language and to effectively communicate cross-culturally. This means that learning a new language involves learning to communicate via both verbal and nonverbal messages. In addition, Gullsunler and Fidan (2011) investigate the use of body language in intercultural communication with examples from Turkey and 
Germany. They conclude their study by stating that although Germans and Turks display some similarities between their uses of body language, cultural differences may cause misunderstanding in body language; therefore, understanding and learning about other cultures, particularly their nonverbal behaviours, is essential to avoid misunderstanding. Ntuli's study Intercultural Misunderstanding in South Africa: An Analysis of Nonverbal Communication Behaviour in Context (2012) further notes that misunderstandings due to cultural differences may negatively affect our relationships with people around us. Accordingly, this study builds upon the previous works noted above to explore how people from different cultures perceive the body language of Saudis at the English Language Institute of King Abdulaziz University.

The next section describes the method used and the participants involved in this study, followed by an analysis of the study data to highlight the main findings relating to nonverbal communication. The discussion and conclusion section investigates the findings in relation to the literature review based on the context of the study.

\section{Participants and Method}

This study involves the participation of 31 instructors from the faculty of the English language institute at King Abdulaziz University. Among the 31 instructors, 10 are from India, 7 are from Pakistan, 3 from Britain, 5 from the United States of America, 1 from China, 1from Japan, 1 from Canada, 1 from South Africa, 1 from Bangladesh, and 1 from the Philippines. All of the instructors live in Saudi Arabia, and communicate with Saudi students and colleagues in the Institute as well as with Saudis outside of the institute. Their length of stay in Saudi Arabia varies from 1 year to more than 7 years; therefore, this factor will be considered as a potential influence on the subjects' understanding and interpretation of Saudis' nonverbal communication.

Data were collected through interviews, which represents a qualitative approach to describing and explaining different attitudes toward body language. Most of the questions of the interview were open-ended in order to elicit more information from the subjects of the study. Through conversations, people are able to clarify their attitudes, feelings, and understandings of life. Therefore, Weiss (1994:14) points out that "the interview provides us with the opportunity to understand more about the "nature of social life". The questions were related to the objectives of the study, which focus on exploring the importance of nonverbal communication in intercultural settings, and the extent to which non-verbal communication 
contributes to the success of communication. Then interviewees were shown photos of common gestures and hand movements that are common in Saudi society, as taken from Al-Seini's 2014 study. Each photo is used to convey certain feelings or attitudes, and an exact description of the gesture is written next to each photo. The participants were asked to try to figure out the meaning of each gesture to determine if it exists in their culture and if it implies the same meaning. All data were analyzed using constructivist grounded theory, in which data go through a coding process that includes open coding, axial coding, and selective coding in order to draw major themes across the entire data set (Dornyei, 2007).

\section{Data Analysis}

It was found that most of the participants viewed nonverbal communication as a complement to verbal communication in the overall process of face-to-face interaction, though mostly used subconsciously. Although most of the participants agree that they do not use much body language while communicating with people who hold higher or authoritative positions, a Chinese participant indicated the existence of protocols in their culture for using body language in formal situations to show respect to older people or to people who hold high positions. On the other hand, nonverbal communication can also be used "when we fall short of words to express ourselves in case there is a language barrier," in the words of one participant. Most of the participants indicated that when communicating with people from other cultures, they use body language and gestures in order to emphasize the meaning they wish to deliver and to ensure that the listener understands that meaning. English instructors typically use body language when teaching vocabulary, adjectives, and tenses, or when they want to motivate, discipline, praise, or show appreciation to the students. They also use body language in class in order to create a friendly, yet formal, rapport with their students.

When the participants were asked if they had encountered miscommunication due to nonverbal factors, most of them had problems with greetings in different cultures, eye contact, pointing, and proxemics (the space between communicators).

Eye contact is an important element in social communication systems. The rules of eye contact can vary immensely from culture to culture. Most of the participants indicated that eye contact is very important in their cultures as it shows respect to the other person and interest in the conversation, as well as honesty and confidence on the part of the speaker. Saudis' perspective towards eye contact is similar to that of Chinese and other East Asian cultures, according to the Chinese participants. For 
both Saudis and Chinese, it is considered impolite to look directly into other people's eyes during a face-to-face conversation, especially when younger people talk to older ones or subordinates talk to superiors. Japanese see prolonged eye contact as a rude and disrespectful act (Coshkun, 2010). According to Varner (2005: 179) "in Western societies eye contact is related to honesty while in other cultures, it is viewed as an invasion of privacy". In addition, eye contact between opposite sexes is not acceptable in Saudi society for religious and social reasons, as lowering the gaze is a sign of chastity and respect. Thus, many participants feel awkward whenever Saudi people avoid eye contact, and because of their lack of knowledge of the Saudi culture, it is uncomfortable and stressful for them when they meet people from another 'eye-contact culture. 'An American participant pointed out, "It is considered rude in my culture not to look at the person's eye while having a conversation. However, conversely, I learned that the person was, in fact, trying not to be rude by looking away."

Proxemics, which refers to the space between the speaker and the listener, is another element of body language that seemed problematic to most of the participants. The proper distance between individuals varies widely among cultures (Varner, 2005). The private space in Middle Eastern culture, for example, is very small. For an American participant, the private space is between $25 \mathrm{~cm}$ and 1 meter. If a stranger enters the private area, the person feels uncomfortable. Saudis widen private space between men and women; whereas in China, because "it is a crowded country, they tend to accept body contact, but when in a less crowded settings, Chinese prefer to have their personal space," a Chinese participant said. This statement suggests that population and lifestyle can also affect the perception of acceptable space between interlocutors. Similarly,an American participant mentioned, "When I first moved here from the states, I felt that there is not a lot of distance between the speaker and the listener which is a bit uncomfortable for me." Such differences might cause miscommunication or misinterpretation of the other person's intentions.

Greetings between people of different cultures may also be a source of miscommunication. For example, Saudis tend to embrace and kiss each other in very close friendships and kinship relations. This practice is seen by most of the participants as confusing due to the differences in the number of kisses on each cheek while greeting and saying hello. The South African participant said, "Males holding hands or kissing on cheeks is unacceptable in my culture, as it shows gay tendencies. "To Saudis, this action is acceptable for a greeting, but people from different backgrounds, especially western societies, may misinterpret it as overly intimate. 
Handshakesare popular greetings all over the world, but it is not acceptable for a male to shake a woman's hand in Saudi society for religious considerations, so it is enough to say the formal greeting to a non mahrammale (a male who is not a close family member like a father, brother, husband, nephew, or uncle). A British participant indicated, "In England, we shake hands with people when we meet them, no matter if the person is a man or a woman. Here, ladies do not shake hands with men." Any touching between males and females, even handshakes , is not approved in Islamic cultures. Similarly, handshakes are not common in Japanese culture, in which people usually greet each other by bowing (Coshkun, 2010). An American participant said, "even the smile might be misinterpreted in Saudi culture. In the west, smiling to a stranger is a sign of politeness. In Saudi culture, smiling to a man is misinterpreted as something bad. "These are basic rules in Saudi society, based on religious and social considerations, that we should respect when communicating with nonmahram males.

The participants described their feelings when encountering miscommunication due to nonverbal factors as "puzzled," "frustrated," "lost," "anxious," "stressed," "irritated," "upset," "angry," "annoyed," and "disappointed." A Pilipino and a Pakistani participant both explained that they feel more comfortable as their knowledge of cultural differences increases. Chen and Starosta (1996) indicate that people can become competent in intercultural communication if they enhance their abilities to negotiate cultural meanings and use effective communication conducts.

Another important point raised in this study is the significance of understanding body language, as used by Saudis, to achieve successful communication. Nearly all of the participants said that this is important, as it is an unavoidable element of communication in face-to-face communication. Most of the participants noted that because one does not want to offend the native people of a country in which one is a guest. One of the participants said, "The use of polite body language opens the channels to acceptance and mutual respect." Another participant said, "a better understanding of Saudi body language can create a better teaching and learning environment. It will encourage students to ask/raise questions when they are confused." An Indian participant raised an important point when she mentioned, "When in Rome, do as Romans do. In the same sense, if we understand Saudi's body language, we would be a part of Saudi." Accordingly, living in a different culture is not an easy experience. If one is planning to live in that culture for a long time, one should understand and learn about this culture.

Most of the participants pointed to the heavy use of body language among Saudis, especially among students. In fact, the heavy use of body language in these cases reflects the need to communicate the correct message in intercultural settings. 
Saudi culture places restrictions on the use of body language in general and hand movements in particular, especially in formal situations or in cases of people of different social standings, such as older and younger people or superiors and subordinates, communicating to one another. However, in intercultural settings, these restrictions are relaxed, because delivering the correct meaning of the message is more important than adhering to social protocols. A Canadian participant said, "Once my student was trying to tell me that she was upstairs, she used her hands in an offended way. I sometimes find the students aggressive." In intercultural communication, body language can either help or hinder understanding. However, to most of the participants, body language is a positive tool in facilitating communication and in delivering the message to compensate for the lack of vocabulary and to overcome the language barrier. "It is a survival technique," a Pilipino participant said.

In the last part of the interview, each participant was shown 11figures of common gestures and hand movements that are common in Saudi society (see appendix 1). They were asked to try to figure out the meaning of each gesture, if the gesture exists in their culture, and if it implies the same meaning. The participants' perception of each figure is discussed in the following part.

Figure 1: A forefinger across the cheek from top to bottom is used to show admiration of something or someone. None of the participants could figure out the implication of this gesture. Most of them thought it expresses thoughtfulness and concentration.

Figure 2: holding the nose with the thumb and the forefinger is used to show that something is bad or smells bad. 11 participants thought that this hand movement indicates a bad smell, and 2 participants said it refers to nose congestions or blowing the nose. The rest indicated that it has something to do with headache, stress, or mental exhaustion.

Figure 3: Touching the area under both eyes at the same time, or one after the other by using the forefinger expresses readiness to do something with pleasure. 2 of the participants said it is used to ensure the accomplishment of a promised task or action, but the rest said it is used to make funny faces, or to tell the other person that I am watching you and I am keeping my eyes on you, or to talk about the dark circles under the eyes. This indicates that only two of the participants got the right implication of this figure, and the rest expressed the descriptive meaning of the hand movement.

Figure 4: A palm with straight and separated fingers toward the face of the other speaker is used to protect oneself from being envied by someone. None of the 
participants could figure out the meaning of this hand movement. They thought it is used to express anger and resentment or to say"stop. "In fact, it is not proper in Saudi society to talk to someone about their talents, wealth, number of children, or other such things, because it reflects an envious act. If it happens, they use this hand movement and say 'allahu akbar' to protect themselves from evil eyes, a social practice known by Saudis.

Figure 5: Putting the hand on the chest with a sigh is used to express satisfaction and relief.22 of the participants could figure out the implication of this hand movement. This is due to the popularity of this movement in many cultures. In addition, it is a descriptive movement because when one is stressed or anxious, one would feel shortness of breath. Accordingly, the feeling of relief takes place in the chest.

Figure 6: Putting the hand on the waist indicated objection and bad attitude. 19 participants viewed this hand movement as an expression of arrogance, anger, impatience, strength, seriousness, and authority. It seems that this movement is used in different cultures to make a statement about one's attitudes toward something. The rest of the participants viewed this movement as a sign of a backache or exhaustion.

Figure 7: Making a circle with the thumb and the forefinger with the other fingers straight and moving the hand up and down expresses a warning. Most of the participants indicated that it is the American-style OK sign to symbolize perfection and excellence. A Pilipino participant said that in her culture, the gesture refers to money.

Figure 8: Combining the edges of the five fingers and moving the hand downward can be used to express either of two meanings, based on the context. One is to express a threat, and the other is to ask for patience. The Canadian participant said that in their culture, this gesture means something is delicious; however, most of the participants understood this gesture to ask for patience. This meaning is more common in intercultural communication, especially in the workplaces and in the classrooms, and it is one of the most popular gestures used by Saudis.

Figure 9: Bringing both forefingers close to each other is used to express closeness between two persons or two objects. Most of the participants could figure out the meaning of this gesture, although it does not exist in their cultures. This may be because the meaning of the movement is descriptive and does not have specific social or religious connotations. 
Figure 10: Raising both hands up to the level of the head signals that it is time to pray. Only two of the participants could figure out the meaning of this gesture. The Indian participants indicate that this gesture is used in their culture to surrender or to give up.

Figure 11: Unfolding the left hand with a palm directed upwards and the right hand formed into a hand grip, placing the gripped hand on the left unfolded hand while moving the right hand in a circle or round movement, is used to tease someone. This gesture does not indicate grinding something, as some of the participants implied, but it refers to the underlying meaning of grinding, which is to tease someone by provoking their anger.

The results of this portion of the study show that the participants could only figure out the meaning of the hand movements that are used more frequently, and which they experience on a daily basis. The longer the participants stayed in Saudi Arabia, the more familiar they became with gestures and nonverbal expressions used by Saudis, as demonstrated by the ability of some of the participants to recognize the meanings of some gestures that do not exist in their cultures but are common in Saudi culture. Motivation also influences the interpretation of gestures: some of the participants are not interested in becoming involved in Saudi culture, because they are or have been there for only a few years, and are thus less motivated to learn nonverbal communication. However, some of these gestures were misinterpreted by the majority of the participants, demonstrating the importance of learning the meanings of body language in different cultures.

In response to the question of how misunderstandings stemming from body language can be avoided or minimized, some participants suggested that one should learn some basics of body language in other cultures, and others said that it is important to learn the etiquette, values, and styles of communication of a country one intends to visit. The internal differences between cultures and the differences in the interpretation of gestures should also be taken into account to avoid miscommunication. In addition, cultural tolerance is important because what may be acceptable or standard in one culture may not be so in others. Most of the participants indicated that nonverbal communication in intercultural settings is essential for appreciating similarities and differences between various cultures.

\section{Discussion and Conclusion}

The main themes observed in this study are the functions of body language, the factors that affect human interactions in general and in intercultural settings in 
particular, and the importance of the communicators' cultural backgrounds in the interpretations of nonverbal communication including body language.

It was found in this study that the functions of the body language depend largely on the context. According to Katan (2004:245), "Context is the amount of information the other person can be expected to posses on a given subject". Accordingly, the function of body language can be either a complement to or a replacement for verbal messages, based on the information the context provides. People from the same background and who share the same culture do not have problems understanding each other's use of body languages. However, in an intercultural context, body language is used to help express the desired meaning, especially in teacher-student communication, due to language barriers. However, the cultural specific properties of gestures and other forms of nonverbal communication might lead to miscommunication, as some gestures maybe interpreted differently in different cultures.

Body language can be consciously or subconsciously realized (Gulsunler and Fidan, 2011). The findings of this study show that the use of body language between people from the same background is subconscious, and it is used to complement the meaning of verbal messages in most cases, whereas in intercultural communication, it is used consciously, especially where language barriers exist. However, the lack of knowledge of other cultures' perceptions toward greeting, eye contact, pointing, and proxemics might lead to miscommunication, as most of the participants of this study have felt uncomfortable because of differences in nonverbal communication factors. One significant observation is that Saudis and East Asians (such as Chinese) share similar perceptions of the space between speaker and listener, as well as of eye contact between people. On the other hand, the participants from western societies perceived some common behaviors in Saudi society differently: for example, they interpreted holding hands and kissing between members of the same sex as indicating homosexuality, while such gestures are normal practices of friendship in Saudi society. This point ties neatly with Burgoon, Buller, and Woodall's (1996:5) findings, which suggest that the interpretation of any message depends on the perception of people who belong to different cultures and might lead to successful communication or to miscommunication.

Register is another factor in the decision of how and when to use body language. People from the same culture tend to use nonverbal cues more in informal situations, but in formal situations, they will depend more on verbal messages. However, East Asian societies tend to use body language in formal situations according to various cultural protocols and expectations within their societies. In 
situations in which the language itself may create a problem with communication, people tend to depend on body language regardless of the formality of the context. This is evident from the instructors who observed and acknowledged significant use of body language by and toward Saudi students. Power imbalances between speaker and listener are also influential factors, as most of the participants noted that body language is less acceptable in their cultures when younger people talk to older people, or when subordinates talk to superiors. This point is further discussed by Kierkegaard (2010).

When the participants interpreted the most common gestures used by Saudis, most of them could only interpret descriptive gestures; many of them could also interpret gestures that are most commonly used in communication with Saudis. However, most of the participants had difficulty deciphering gestures that had specific social or religious connotations. The culture-specificity of nonverbal cues such as these demonstrates the potential for misinterpretation and thus for communication breakdowns. Therefore, research on the similarities and differences between different cultures is needed as a greater defense against misunderstanding. Such research can be used to raise awareness of the obstacles that might be encountered in intercultural contexts in our increasingly globalized world.

\section{References and notes:}

Aghayeva, K., 2011, Different Aspects of Intercultural Nonverbal Communication. Khazar Journal of Humanities and Social Sciences, 14(2), 53-62.

Alseini, R., 2014. The Effect of Hand Movements on Communication in Saudi Society. Unpublished Paper. King Abdulaziz University.

Anderson, P., Peter, A., Hecht, M., Hoobler, G. and Smallwood, M., 2002. Nonverbal Communication across Cultures. In W. Gudykunst and B. Mody, eds.Handbook of International and Intercultural Communication. London: Sage Publication, 89-106.

Bassist, S, Gelles, J. and Levine,A., 1991.Sociology: An Introduction. New York: McgrawHill.

Burgoon, J., Buller, D. and Woodal, W., 1989. Nonverbal Communication: The Unspoken Dialogue.Newyork: Harper and Row.

Burgoon, J., Buller, D. and Woodall, W., 1996. Nonverbal Communication: The Unspoken Dialogue. New York: Mcgraw-Hill.

Coshkum, A., 2010, Whose English Should We Teach? Reflections from Turkey.Esp World, 9(27), 1-20.

Damanhouri, M., 2015,The effect of early and heavy exposure to a second language on the recognition of certain Arabic phonemes: A Case Study. ARECLS, 12, 138-157.

Dornyei, Z., 2007. Research Methods in Applied Linguistics. Oxford: Oxford University Press.

Gullberg, M., 2013.Gesture Analysis in Second Language Acquisition. Blackwell Publishing. 
Gullsunler, M. and Fidan, M., 2011, An Empirical Work about the Use of the Body Language in Intercultural Communication: Examples of Turkey and Germany. International of Arts and Science, 4(3), 9-16.

Kárpáti. L; 2017. The use of communication strategies in English language education”, International Journal of Humanities and Social Development Research, Volume 1(2).Baku. pp. 5-14

Katan, D., 2004. Contexting. In D. Katan, ed.Translating Cultures. St. Jerome, 245-257.

Kikegaard, T., 2010. An Analysis of Non-Verbal Communication within the Organizational Culture of Japan. Zurich:Ba- Project, C.G. Jung Institute.

Kooper, K., 1989. SözsüzIletişim.Istanbul: IlgiYayınevi.

Makbule, G. and Mehmet, F., 2011, An Empirical Work about the Use of Body Language in Intercultural Communication: Example of Turkey and Germany. International Journal of Arts \& Sciences, 4(3), 9-16.

Mcneill, D., 2000. Language and Gesture. New York: Cambridge University Press.

Novinger, T., 2001. Intercultural Communication: A Practical Guide. USA: University Of Texas Press.

Ntuli, C., 2012, Intercultural Misunderstanding in South Africa: An Analysis of Nonverbal Communication Behavior in Context. Intercommunication Studies, 21(2), 20-31.

Özüorçun, F., 2013, The Importance of Body Language in Intercultural Communications. Eul Journal of Social Sciences, 4(2), 70-81.

Sharifiabad, M. and Vali, S., 2011, A Comparative Study of Native and Non-Native Body Language. Journal of Intercultural Communication, 26:6.

Shi, Y. and Fan, S., 2010, An analysis of Nonverbal Behavior in Intercultural Communication.The International Journal- Language Society and Culture, 31, 113-120.

Varner, I., 2005. Nonverbal Language in Intercultural Communication. In I. Varner, ed., Intercultural Communication in the Global Workplace, Mcgraw-Hill,175-203.

Weiss, R., 1994.Learning from Strangers: The Art and Method of Qualitative Interview Studies. New York: Free Press; Maxwell Macmillan International. 
Summary

\title{
The advantages and disadvantages of body language in Intercultural communication
}

\author{
Miramar Damanhouri \\ King Abdulaziz University, Saudi Arabia
}

This study is an attempt to explore the advantages and disadvantages of non-verbal communication, specifically body language, in intercultural settings, and the extent to which non-verbal factors contribute to the success of communication, by interviewing 31 English language instructors at the English language Institute at King Abdulaziz University. The instructors came from different cultural backgrounds and their length of stay in Saudi Arabia varies from 1 year to more than 7 years. The findings show that although the main function of body language in an intercultural setting is to clarify meaning when language is a barrier, the difference in cultural backgrounds sometimes leads to miscommunication or misinterpretation of nonverbal messages. However, almost all the participants considered body language a positive tool in facilitating communication and compensating for the lack of vocabulary in intercultural communication. More research on the similarities and differences between cultures with regard to nonverbal communication is recommended, in order to avoid or minimize misunderstandings that may result from cultural and linguistic differences.

Key words: Intercultural communication- body language - miscommunication 
Miramar Damanhouri

\section{Appendix}

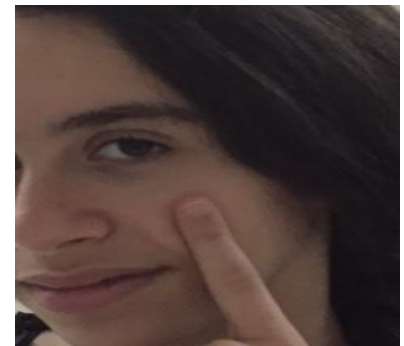

Figure 1

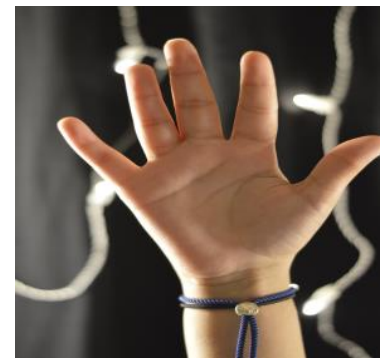

Figure 4

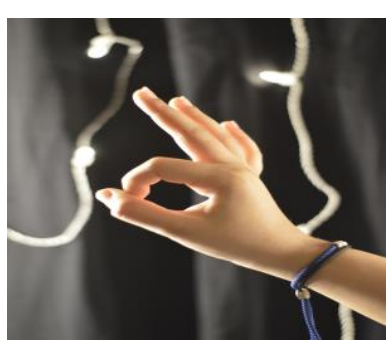

Figure 7

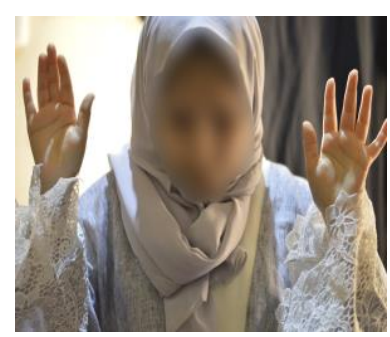

Figure 10

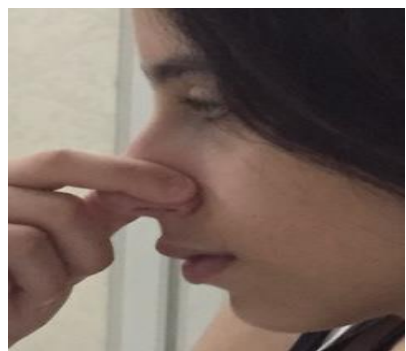

Figure 2

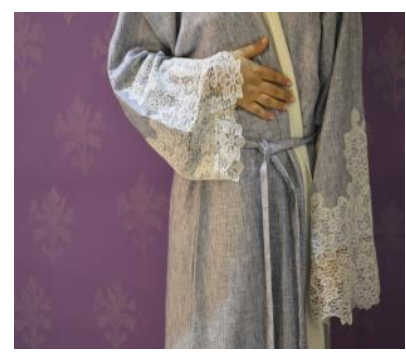

Figure 5

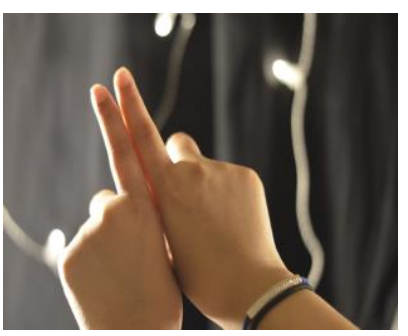

Figure 8

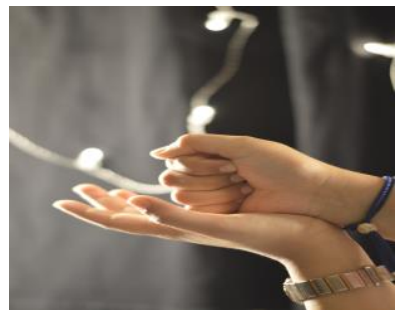

Figure 11

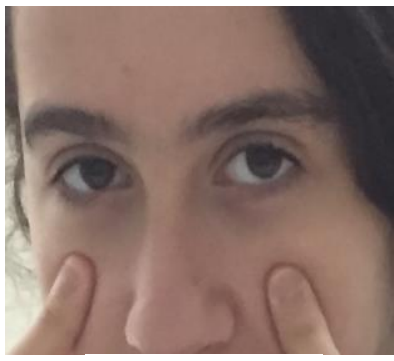

Figure 3

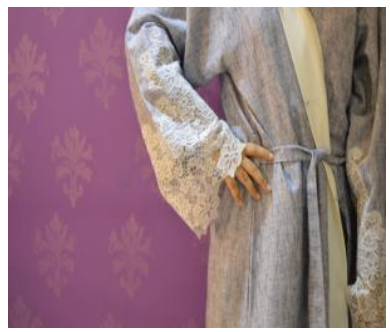

Figure 6

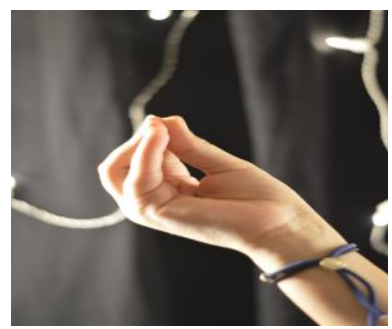

Figure 9 